\title{
ÚNG DỤNG MÔ HÌNH THỦY LỬC HAI CHIỀU TÍNH TOÁN NGẬP ÚNG CHO ĐÔ THI VEN BIỄN - ÚNG DỤNG TẠI QUẬN NINH KIỀU, THÀNH PHỐ CẦN THƠ
}

\author{
Nguyễn Quang Hưng ${ }^{*}$, Nguyễn Phước Thọ²
}

Tóm tắt: Ngập lụt trong đô thị càng ngày càng trở nên một vấn đề cấp bách và bức xúc trong đời sống của ngườ dân. Mô hình toán thủy văn đô thị đã được chưng tỏ trong nhiều ứng dụng nghiên cứu có khả năng mô phỏng tính toán các quá trình mưa, dòng chảy, dòng chảy trong cống cũng nhu ngập lụt trên bề mặt đô thị. Trong nghiên cứu này nhóm tác giả đã sủ dụng bộ phần mềm Mike Urban để đánh giá khả năng mô phỏng quá trình ngập lưt có sự ảnh hưởng mạnh của nuớc triều tại lưu vực quận Ninh Kiều, thành phố Cần Tho: Kết quả cho thấy diê̂n biến ngập lụt do mura, triều dâng đã được diễn tả đầy đủ chính xác. Tù các kết quả của mô hình, nguyên nhân gây ngập úng cũng nhu một số giải pháp đã được đề xuất nhằm ứng phó với các diễn biến phức tạp trong truơng lai nhu biến đổi khi hậu, nuớc biển dâng. Kết quả cũng khẳng định sức mạnh ứng dụng thực tế của các mô hình thủy văn thủy lực tính toán 2 chiều trong việc thiết kế, vận hành và quản lý thoát nuớc đô thị cho các thành phố ven biển.

Từ khóa: Thủy văn đô thị, ngập lụt, nước triều dâng, mô hình đô thị bền vĩng.

Ban Biên tập nhận bài: 11/12/2019 ～Ngày phản biện xong: 12/12/2019 ～Ngày đăng: 20/12/2019

\section{1. Đặt vấn đề}

Ngập lụt đô thị ngày càng trở nên cấp bách và xuất hiện với tần suất nhiều hơn, nguyên nhân nhiều là do quy hoạch sai, thiết kế sai, vận hành và bảo dưỡng không đúng, thiếu vốn, không đồng bộ, ý thức bảo vệ hệ thống thoát nước kém, nước triều dâng, mưa dao động. Trong tính toán thiết kế của Việt Nam cũng đã có các quy định cụ thể về tính toán thoát nước thải, thoát nước mưa [2], tuy nhiên có thể thấy vấn đề hệ thống thoát nước đô thị của các thành phố ven biển (các vùng có bị ảnh hưởng của nước triều) thì chưa được quan tâm và hoàn toàn không có các tiêu chuẩn tính toán cụ thể. Do đó, để hỗ trợ nâng cao tính chính xác và đúng đắn của thiết kế, việc sử dụng các mô hình thủy văn đô thị đang là một giải pháp đúng đắn và cần được xem xét nghiêm túc để trở thành một công cụ chính thống trong thiết kế, vận hành và quản lý hệ thống thoát nước.

Các loại ngập lụt trong đô thị có thể kể đến một số dạng như: (1) Ngập do nước chảy tràn trên bề mặt khi không có cống hoặc hệ thống cống bị tắc; (2) Ngập do tắc cống cục bộ, dẫn đến nước không được vận chuyển, bị ùn tắc và dâng lên tại các hố thăm; (3) Ngập do mưa lớn, toàn bộ hệ thống không đảm nhận được khả năng tiếp nhận và vận chuyển nước mưa nên nước ngập đầy dưới cống và trào ngược lên trên mặt đất; (4) Ngập do nước triều xâm nhập vào hệ thống thoát nước, dâng ngược trở lại mặt đất.

Các nguyên nhân gây ngập úng cho các đô thị Việt Nam đã được các nhà khoa học và quản lý tổng kết lại qua nhiều nghiên cứu, trao đổi tại các hội thảo bao gồm: (1) Mưa lớn, lũ từ thượng nguồn đổ về; (2) Thủy triều xâm nhập qua hệ

${ }^{1}$ Khoa Khí tương Thủy văn và Hải durơng hoc,

Đại hoc Khoa hoc Tư nhiên, ĐHQGHN,

${ }^{2}$ Đài Khi tuoọng Thủy văn tỉnh Cần Tho.

Email:hungnq@hus.edu.vn 
thống thoát nước; (3) Sụt lún nền đô thị, cao độ mặt nền thấp; (4) Hệ thống hạ tầng (bao gồm cả hệ thống thoát nước) bị quá tải, thiết kế sai, vận hành và bảo trì kém, dẫn đến không thực hiện được nhiệm vụ thoát nước; (5) Thiếu quy hoạch và quản lý đồng bộ về cơ sở hạ tầng; (6) Khả năng dự báo, cảnh báo kém, chưa đáp ứng được, đặc biệt với yêu cầu dự báo cực ngắn cho các ứng dụng của đô thị.

Do đó, để giải quyết vấn đề ngập úng cho mỗi đô thị hoặc một khu vực riêng biệt, cần xác định rõ loại ngập lụt nào là chủ yếu và nguyên nhân chính là do đâu để có thể ưu tiên tập trung giải quyết.

Các đô thị của Việt Nam đều đang phát triển mạnh mẽ, mở rộng cơ sở hạ tầng, mật độ dân số tăng mạnh do cư dân nhiều khu vực nông thôn du nhập về, dẫn đến tình trạng thoát nước đang trong tình trạng quá tải, ngay cả ở các thành phố đã được triển khai xây dựng hệ thống thu gom và xử lý nước thải. Với gần 130 đô thị dọc trên 3000 km bờ biển, hiện tượng ngập lụt đô thị đang xảy ra và sẽ trở thành một vấn đề nhức nhối không loại trừ với bất cứ đô thị nào.

Chính vì thế, cần có một sự quan tâm kịp thời tới việc triển khai tính toán và thiết kế hệ thống thoát nước cho các đô thị, đặc biệt cần quan tâm tính toán ảnh hưởng của triều đến hệ thống của các đô thị ven biển. Cùng với sự phát triển của công nghệ khoa học, ứng dụng của mô hình toán để mô phỏng các hiện tượng tự nhiên đang ngày càng trở thành một công cụ hữu ích, chính xác và tiện lợi, được sử dụng trong rất nhiều ngành, từ nông nghiệp, lâm nghiệp, hải sản, đến các ngành xây dựng công trình, thiết kế xây lắp.... Các mô hình toán thủy văn cũng được phát triển mạnh mẽ, cùng với khả năng tính toán của các máy tính đang mang lại khả năng vô tận của việc mô phỏng, tính toán tối ưu các hiện tượng từ đơn giản tới phức tạp trong chu trình thủy văn trên trái đất. Chính vì thế, trong nghiên cứu này, các tác giả mong muốn sử dụng mô hình thủy văn và thủy lực tính toán lan truyền 2 chiều để kiểm tra khả năng ứng dụng vào trong mô phỏng hệ thống thoát nước tại khu vực quận Ninh Kiều, Cần Thơ, đánh giá được độ chính xác, thời gian phản hồi cũng như chi tiết các kết quả của mô hình có thể mang lại. Đặc biệt, tác động của nước triều dâng đến ngập úng đô thị được nghiên cứu cẩn thận và so sánh đánh giá bằng những số liệu thực đo tại khu vực nghiên cứu.

Thorndahl và Willems (2008) [3] đã sử dụng mô hình MOUSE kết hợp với phương pháp Độ tin cậy bậc 1 để đánh giá hiệu quả sử dụng các thành phần trong hệ thống thoát nước của thị trấn Frejlev - Đan Mạch. Thị trấn có lưu vực khoảng 87 ha và dân số khoảng 2000 người, hệ thống thoát nước của thị trấn bao gồm các hệ thống cống ngầm và các cửa xả dẫn vào con suối chảy qua gần thị trấn. Để phòng chống hiện tượng nước chảy tràn ngược từ suối vào cống, các cửa xả đều được xây với các thiết bị ngăn tràn.

Theo Thorndahl và Willems phương pháp kết hợp này có lợi thế hơn so với phương pháp truyền thống là thời gian mô phỏng có thể được giảm $1 \%$. Tuy nhiên, mô phỏng với phương pháp kết hợp này chỉ cho kết quả từ một cửa cống tại một thời điểm trong khi phương pháp truyền thống cho ta kết quả từ tất cả các hố ga. Việc thực hiện phương pháp này chỉ được công nhận đối với một lưu vực mà nước được vận chuyển nhờ lực hấp dẫn chứ không phải là một lưu vực với nhiều máy bơm [3].

Apirumanekul và Mark (2001) đã thiết lập mô hình tính toán mô phỏng hiện trạng lũ lụt cho thành phố Dhaka, Banglades. Trận mưa điển hình năm 1996 được sử dụng và kết quả cho thấy hiện tượng ngập úng xảy ra với độ sâu ngập lên tới $55 \mathrm{~cm}$ và kéo dài trong 16 giờ, hoàn toàn khớp với thực tế. Các tác giả đã đưa ra các giải pháp sử dụng máy bơm để chống ngập và hiệu quả của các máy bơm cũng đã được đánh giá thông qua mô hình ngập lụt đô thị này. Thời gian ngập đã được giảm xuống chỉ còn 7 tiếng đồng hồ, tính toán cũng chỉ ra nếu nạo vét tại các điểm quan trọng được xác định từ mô hình thì thời gian ngập cũng giảm và độ sâu ngập cũng được cải thiện đáng kể [4]. 
Trong năm 2002, lượng mưa và hệ thống dự báo lũ lụt đã được phát triển tại Bangkok trong một dự án nghiên cứu được tiến hành bởi Viện Công nghệ Châu Á (AIT, Thái Lan) và DHI (Đan Mạch). Mục tiêu đầu tiên là cung cấp lượng mưa đáng tin cậy và dự báo lũ lụt dựa trên cả hai radar và hệ thống các trạm đo mưa bằng gầu.

Lượng mưa dự báo đã được dựa trên một radar thời tiết (Cục Khí tượng Thái Lan, TMD) nằm trong khu vực trung tâm thành phố cùng với một mạng lưới gồm 47 điểm đo mưa (Đô thị Bangkok, BMA).

Hệ thống thoát nước đô thị của một phần thành phố Bangkok được mô hình hóa với một mô hình hai lớp $1 \mathrm{D}$ - 1D mô tả đường phố và lớp hệ thống cống thoát nước. Dự án này đã được xây dựng với mô hình MOUSE và đầu vào của mô hình là lượng mưa dự báo. Việc sử dụng các mô hình trực tuyến này cho phép mở rộng khả năng dự báo cho tương lai của hệ thống thoát nước, bao gồm cả mức độ dự kiến lũ lụt trong mô hình. Kết quả mô phỏng ngập lụt được sử dụng trong một chương trình cảnh bảo lũ thời gian thực [5].

\section{Phương pháp nghiên cứu và thu thập tài liệu}

\subsection{Giới thiệu mô hình thủy văn đô thị}

Trong nghiên cứu này, phương pháp mô hình toán 2 chiều được ứng dụng để tính toán mô phỏng và dự báo tình trạng ngập lụt của khu vực nghiên cứu.

Mô hình Thủy văn đô thị bao gồm hai phần chính là thủy văn và thủy lực. Mô hình thủy văn sẽ xử lý mô phỏng các quá trình hình thành dòng chảy bề mặt từ mưa, có xét đến các quá trình điền trũng, thấm, bốc hơi, dòng chảy bề mặt, dòng chảy sát mặt, dòng chảy cơ sở, ... thông qua các phương trình thủy văn sẽ tính toán được dòng chảy của các tiểu lưu vực trên khu vực tính toán. Các thông số được xem xét đến đối với mô hình Thủy văn bao gồm các thông số bề mặt lưu vực như phần trăm diện tích thấm, độ ẩm của đất, các thông số đặc trưng khả năng thấm và bốc hơi, tính chất của thảm phủ, diện tích lưu vực, độ dốc....

Mô hình thủy lực: mô hình giải quyết bài toán dòng chảy một chiều sử dụng phương trình Saint-Venant để mô phỏng các quá trình dòng chảy trong mạng lưới đường ống thoát nước, bao gồm cả các thiết bị phức tạp như máy bơm, cửa, đập tràn, van... Chất lượng của các mô hình này phụ thuộc vào chất lượng của dữ liệu đầu vào và quá trình hiệu chỉnh. Mô hình 1 chiều thường xử lý dòng chảy có áp và tự do. Biên sử dụng trong mô hình thường là dòng chảy lưu vực hoặc dòng chảy mùa khô tại các biên thu nước và mực nước tại các cửa ra. Như vậy bước tính toán sẽ là lần lượt tính toán mô hình thủy văn, sau đó sử dụng kết quả đầu ra của mô hình thủy văn để đưa vào tính toán tiếp trong mô hình thủy lực. Kết quả ta sẽ thu được các đặc trưng vật lý dòng chảy trong kênh mương (vận tốc, độ sâu mực nước, lưu lượng). Tuy nhiên nếu chỉ dừng lại ở mô hình thủy lực 1 chiều thì kết quả chưa thể hiện được đầy đủ các trường hợp ngập lụt trên bề mặt.

Để nâng cao chất lượng của mô hình Thủy văn đô thị, các tính toán thủy lực được mở rộng tính toán 2 chiều, kết hợp với bản đồ mô hình số độ cao để mô phỏng chi tiết nước chảy tràn trên bề mặt lưu vực. Rõ ràng trong trường hợp này, bản đồ mô hình số độ cao đóng vai trò quan trọng quyết định đến độ chính xác của kết quả.

Trong nghiên cứu này, mô hình Mike Urban đã được lựa chọn để sử dụng vì khả năng mạnh mẽ trong tính toán cũng như tính ứng dụng của mô hình đã được kiểm chứng qua rất nhiều các công bố khoa học. Đặc biệt mô hình Mike Urban có khả năng mở cho chúng ta lựa chọn làm việc ở chế độ tính toán thủy lực 1D hay mở rộng chi tiết hoá mô phỏng 2D.

\subsection{Giới thiệu lưu vục nghiên cúu và số liệu thu thập}

Cần Thơ nằm ở trung tâm Đồng bằng sông Cửu Long (ĐBSCL), là điểm giao nhau của vùng Tây Nam sông Hậu với vùng Tứ giác Long Xuyên, vùng Bắc sông Tiền và vùng trọng điểm phía Nam. Thành phố Cần Thơ được xem là trung tâm kinh tế, văn hóa và chính trị của 
ĐBSCL, cũng là thành phố hiện đại và lớn nhất của cả vùng hạ lưu sông Mê Kông. Thành phố nằm giữa một mạng lưới sông ngòi, kênh rạch chằng chịt. Ninh Kiều là quận trung tâm của thành phố Cần Thơ, nằm ở ngã ba sông Cần Thơ và sông Hậu, phía đông giáp tỉnh Vĩnh Long, phía tây giáp huyện Phong Điền, phía nam giáp huyện Phong Điền và quận Cái Răng, phía bắc giáp quận Bình Thủy

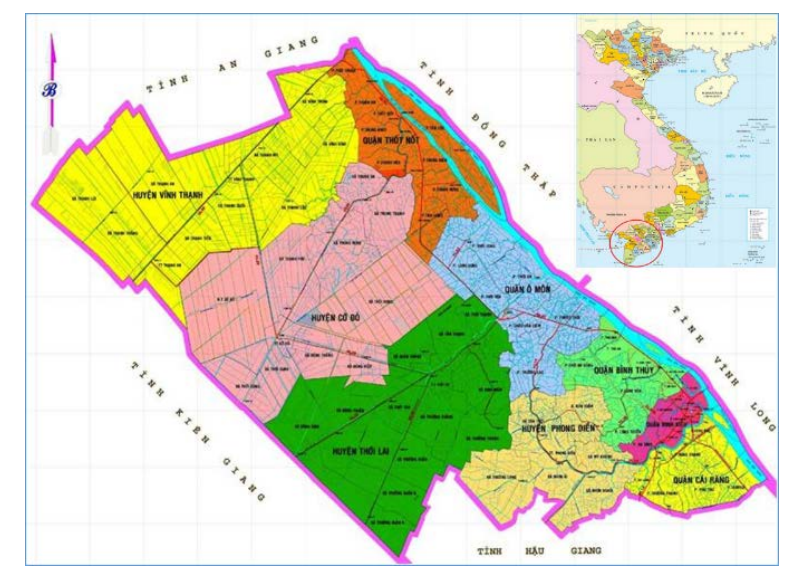

\section{Hình 1. Bản đồ hành chính Cần Tho và Ninh Kiều}

Hàng năm, vào mùa mưa, do nước lũ từ thượng nguồn sông Mê Kông đổ về và mưa nội đồng, ĐBSCL bị ngập với một diện tích lớn ở phía Bắc. Thực trạng diễn biến ngập trên địa bàn TP. Cần Thơ ngày càng tăng cả về diện tích và mức ngập, mức ngập 0,25 - 2,0m không chỉ gây thiệt hại nặng nề cho khu vực sản xuất nông nghiệp mà còn ảnh hưởng lớn đến một số tuyến đường, khu vực đô thị của thành phố, đặc biệt là tại quận Ninh Kiều và Bình Thủy.

Tại thành phố Cần Thơ trong những năm gần đây, ngập lụt ảnh hưởng lên một khu vực rộng lớn với diện tích trung bình 2.000 ha (khoảng $69 \%$ tổng diện tích đô thị lõi) và hơn 200.000 người bị ảnh hưởng (bao gồm cả người nghèo) mỗi năm. Theo báo cáo Quy hoạch thoát nước thành phố Cần Thơ, ngập lụt đô thị gây ra thiệt hại kinh tế trực tiếp hơn 300 triệu USD trong 5 năm qua.

Hệ thống thoát nước hiện tại của thành phố trong những năm qua tuy đã được đầu tư, nâng cấp cải tạo nhưng vẫn chưa đủ khả năng để ngăn ngừa nước tràn từ sông vào, đặc biệt là trong mùa mưa lũ. Thêm vào đó, hệ thống tiêu thoát nước nhìn chung đã cũ, không đủ khả năng đối phó với các cơn mưa lớn và triều cường, nhiều khu vực của thành phố vẫn chưa có hệ thống thoát nước. Cùng với việc đô thị hóa tăng nhanh, công tác quản lý xây dựng đô thị còn lỏng lẻo, không kiểm soát dẫn đến việc lấn chiếm rất nhiều kênh rạch tự nhiên, giảm thiểu đáng kể khả năng thoát nước của hệ thống thoát nước tự nhiên.

Quận Ninh Kiều: hầu hết các phường của quận đều bị hiện tượng ngập úng, độ ngập phổ biến từ $30-40 \mathrm{~cm}$, kéo dài vài giờ, đặc biệt 1 số khu vực có độ ngập 40 - 50 cm như đường Lý Tự Trọng (P. An Cư), đoạn Cầu Đường (P.An Khánh), hẻm 232 đường 30/4 (P. Hưng Lợi)... thời gian ngập kéo dài 2 - 3 giờ, riêng hẻm 232 đường 30/4 ngập từ $2-3$ ngày.

\subsection{Thiết lập mô hình Thủy văn đô thị cho quận Ninh Kiều}

Dựa trên các số liệu thu thập được, mô hình thủy văn đô thị cho quận Ninh Kiều được thiết lập trong phần mềm Mike Urban với mục tiêu tính toán mô phỏng 2 chiều. Do đó, mô hình số độ cao được quan tâm và dành nhiều thời gian để triển khai, số liệu từ các trung tâm dữ liệu quốc tế và các số liệu điều tra khảo sát thực tế.

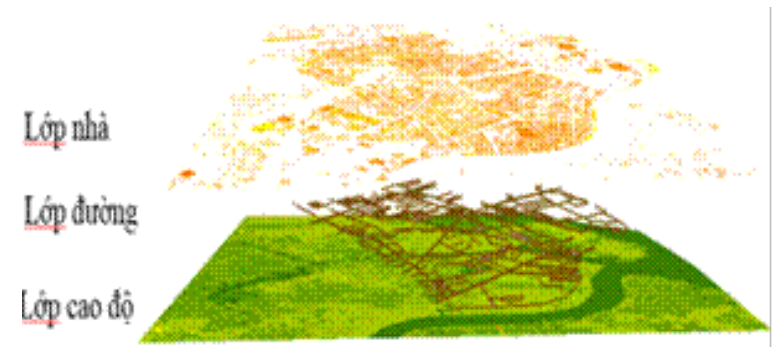

Hình 2. Biên tập DEM với lớp nhà và lóp đường

Nguồn số liệu gốc cơ bản của mô hình số cao độ được tổng hợp từ các nguồn số liệu quốc tế với độ phân giải 30x30m, sau đó được làm giàu số điểm dựa trên số liệu cao độ khảo sát dọc tuyến thông qua các dự án đầu ư xây dựng hệ 
thống thoát nước, cũng như các số liệu dạng $(\mathrm{x}, \mathrm{y}, \mathrm{z})$ từ các đợt khảo sát kỹ thuật trong các dự án làm đường, xây dựng cơ sở kỹ thuật hạ tầng và bản đồ quy hoạch thủy lợi. Các dữ liệu này được chồng xếp và nội suy để xây dựng bản đồ DEM cơ bản, đi cùng với các thông tin về lớp thảm phủ, diện tích thấm nước, thời gian tập trung nước, hệ số thấm, mật độ dân cư .v.v. Lớp đường được tạo ra từ các shape file đường, và được coi như thấp hơn với bề mặt cốt mặt đất một khoảng $20 \mathrm{~cm}$, có chiều rộng là $20 \mathrm{~m}$. Một trong những điểm quan trọng của lưu vực đô thị là các công trình cơ sở hạ tầng như nhà cửa, cầu vượt, sân bãi... đóng vai trò quan trọng trong việc xác định đường đi của dòng chảy tràn. Nếu không có thông tin giữa hai điểm $\mathrm{A}$ và $\mathrm{B}$ thì dòng chảy tràn có thể được tính chảy trực tiếp từ $\mathrm{A}$ đến $\mathrm{B}$, nhưng rõ ràng nếu có tòa nhà chắn giữa, thì dòng chảy sẽ đổi hướng, tăng khả năng gây úng cục bộc... Chính vì vậy, lớp nhà đã được tạo ra bằng phương pháp số hóa dựa trên các bản đồ của khu vực nghiên cứu, thể hiện đầy đủ các đơn vị hạ tầng dưới dạng các block. Trong nghiên cứu này, DEM sử dụng là DEM 10x10m, với mục tiêu là lưới tính toán đủ nhỏ chi tiết để mô phỏng và không quá dày gây ảnh hưởng tới tốc độ tính toán của mô hình. Với kích thước DEM 50x50m, hệ thống sẽ bỏ qua rất nhiều tính năng trong mô hình, ví dụ các đường nhỏ, các khu nhà đơn lẻ có kích thước nhỏ hơn của ô lưới. Nếu chọn kích thước $1 \times 1 \mathrm{~m}$ hoặc $5 \times 5 \mathrm{~m}$, cao độ số có khả nang mô phỏng rất chi tiết quá trình chảy tràn bề mặt, tuy nhiên tổng số bước tính toán đã trở nên quá lớn, dẫn đến việc thời gian tính toán lâu, mô hình mất đi tính thời gian thực

Khu vực quận Ninh Kiều là khu vực độc lập, ba mặt bao bọc với các đê, do đó không có biên mở 2 chiều trên bề mặt, chỉ có biên mực nước triều được trích xuất từ trạm đo Cần Thơ và các số liệu từ bộ mô hình Mike 11 để tạo các biên sông bao xung quanh khu vực. Các biên sông này được liên kết với mô hình thông qua các chế độ mực nước sông tại cửa xả cả mô hình. Đây cũng chính là các điểm có các biên mở 2 chiều trên bề mặt, mô phỏng quá trình nước biển dâng tràn qua bờ chảy vào trong nội địa quận Ninh Kiều trên bề mặt đất.

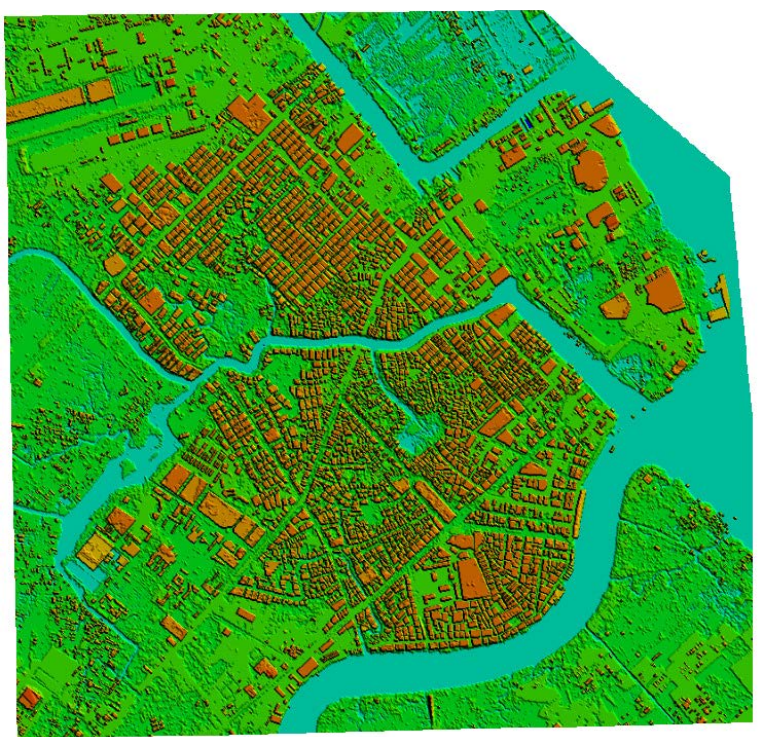

Hình 3. Mô hình số cao độ được sủ dụng trong mô hình Mike Urban với các lóp nhà và đường

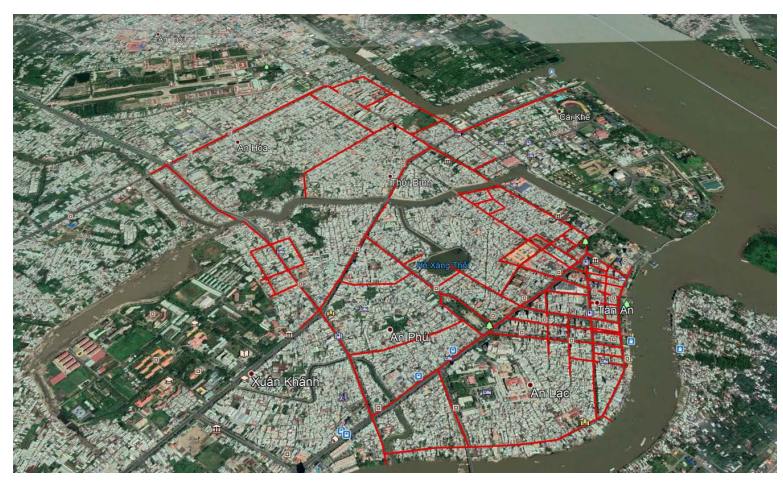

Hình 4. Hệ thống thoát nước quận Ninh Kiều đurợc mô hình hóa trong Mike Urban

Hệ thống cống và kênh mương thoát nước cũng như sông Hậu đã được đưa vào mô hình gồm 184 nút tính toán, 234 đường ống kết nối với tổng chiều dài gần $40 \mathrm{~km}$ thể hiện kênh rạch, cống thoát nước, và 175 tiểu lưu vực cùng với 11 cửa xả nước vào sông Hậu đã được mô tả trên hình 5 . 


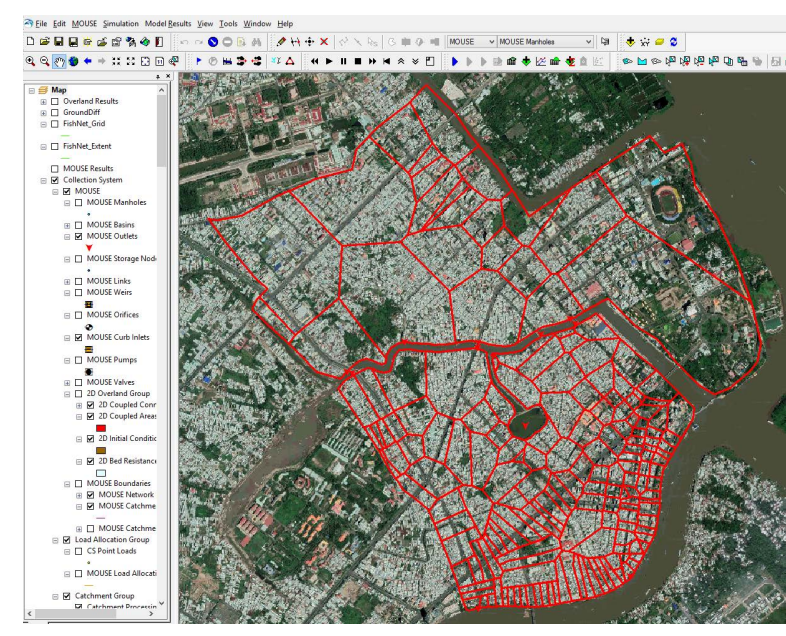

Hình 5. Hệ thống tiểu lưu vực thoát nước quận Ninh Kiều trong Mike Urban

\section{Kết quả và thảo luận}

\subsection{Kết quả hiệu chỉnh và kiểm định mô}

\section{hình}

Trận mưa sử dụng để hiệu chỉnh mô hình là trân mưa kéo dài từ 11 đến 13 tháng 9 năm 2019 , biên triều cũng được đưa vào mô hình.

Kết quả tính toán cho thấy tại 26 điểm ngập trên khu vực quận Ninh Kiều đều đã được hiệu chỉnh đạt mức độ chính xác mực nước ngập dưới $15 \mathrm{~cm}$, rất nhiều điểm ngập có độ chính xác dưới $5 \mathrm{~cm}$

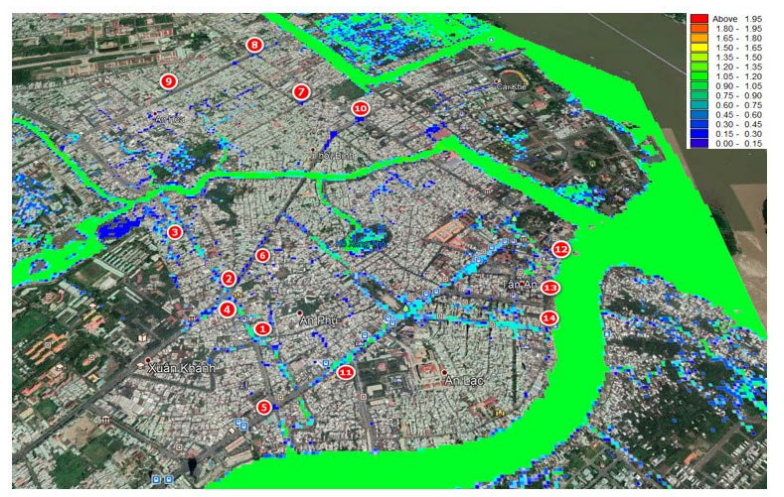

Hình 6. Kết quả mô phỏng trận mưa ngày 1113 tháng 9 năm 2018

Giữ nguyên bộ thông số vừa kiểm định, hiệu chỉnh mô hình với trận mưa ngày 9 đến 11 tháng 10 năm 2018, thu được các kết quả như sau:
Bảng 1. Kết quả so sánh độ sâu ngập lớn nhất thực đo và tính toán tại một số vị trí điển hình trận ngập 12/9/2018

\begin{tabular}{|c|c|c|c|c|}
\hline STT & Tuyến đường & $\begin{array}{l}\text { H thực } \\
\text { đo (m) }\end{array}$ & $\begin{array}{l}\text { H tính } \\
\text { toán } \\
\text { (m) }\end{array}$ & $\begin{array}{l}\Delta \mathbf{H} \\
(\mathbf{m})\end{array}$ \\
\hline 1 & \multirow{4}{*}{ Mậu Thân } & 0.2 & 0.13 & 0.07 \\
\hline 2 & & 0.2 & 0.18 & 0.02 \\
\hline 3 & & 0.2 & 0.3 & 0.1 \\
\hline 4 & & 0.2 & 0.3 & 0.1 \\
\hline 5 & Đường 30 tháng 4 & 0.1 & 0.05 & 0.05 \\
\hline 6 & Trần Hưng Đạo & 0.1 & 0.1 & 0 \\
\hline 7 & Phạm Ngũ Lão & 0.3 & 0.25 & 0.05 \\
\hline 8 & \multirow{2}{*}{ Nguyễn Văn Cừ } & 0.2 & 0.14 & 0.06 \\
\hline 9 & & 0.1 & 0.12 & 0.02 \\
\hline 10 & CMT8 & 0.15 & 0.13 & 0.02 \\
\hline 11 & Quang Trung & 0.45 & 0.3 & 0.15 \\
\hline 12 & \multirow{6}{*}{ Hai Bà Trưng } & 0.2 & 0.21 & 0.01 \\
\hline 13 & & 0.1 & 0.04 & 0.06 \\
\hline 14 & & 0.2 & 0.18 & 0.02 \\
\hline 15 & & 0.2 & 0.3 & 0.1 \\
\hline 16 & & 0.1 & 0.04 & 0.06 \\
\hline 17 & & 0.2 & 0.29 & 0.09 \\
\hline 18 & \multirow{2}{*}{ Nguyễn Văn Trỗi } & 0.15 & 0.3 & 0.15 \\
\hline 19 & & 0.15 & 0.11 & 0.04 \\
\hline 20 & Nguyễn Cư Trinh & 0.15 & 0.15 & 0 \\
\hline 21 & Đinh Công Tráng & 0.1 & 0.1 & 0 \\
\hline 22 & Đường 3 tháng 2 & 0.2 & 0.3 & 0.1 \\
\hline 23 & Cao Thắng & 0.15 & 0.14 & 0.01 \\
\hline 24 & Nguyễn Ngọc Trai & 0.15 & 0.12 & 0.03 \\
\hline 25 & $\begin{array}{l}\text { Nguyễn Thị Minh } \\
\text { Khai }\end{array}$ & 0.2 & 0.1 & 0.1 \\
\hline 26 & Ung Văn Khiêm & 0.2 & 0.11 & 0.09 \\
\hline
\end{tabular}

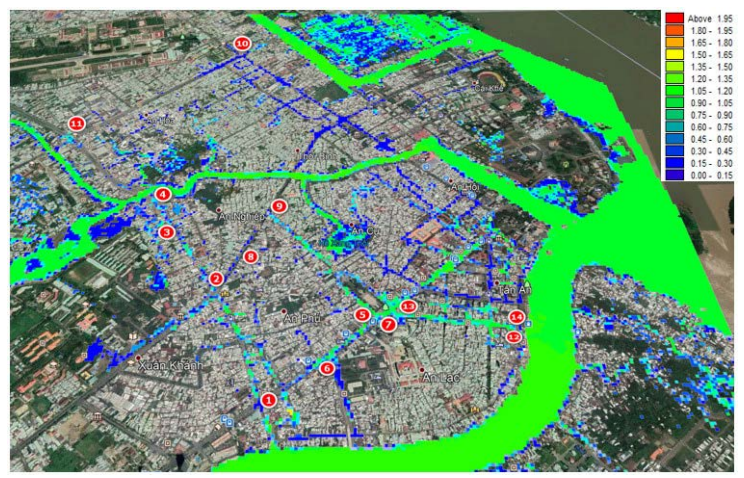

Hình 7. Kết quả mô phỏng trận mưa ngày 9-11 tháng 10 năm 2018 
BÀI BÁO KHOA HỌC

Bảng 2. Kết quả so sánh độ sâu ngập lớn nhất và tính toán tại một số vị trí điển hình trận

ngập 10/10/2018

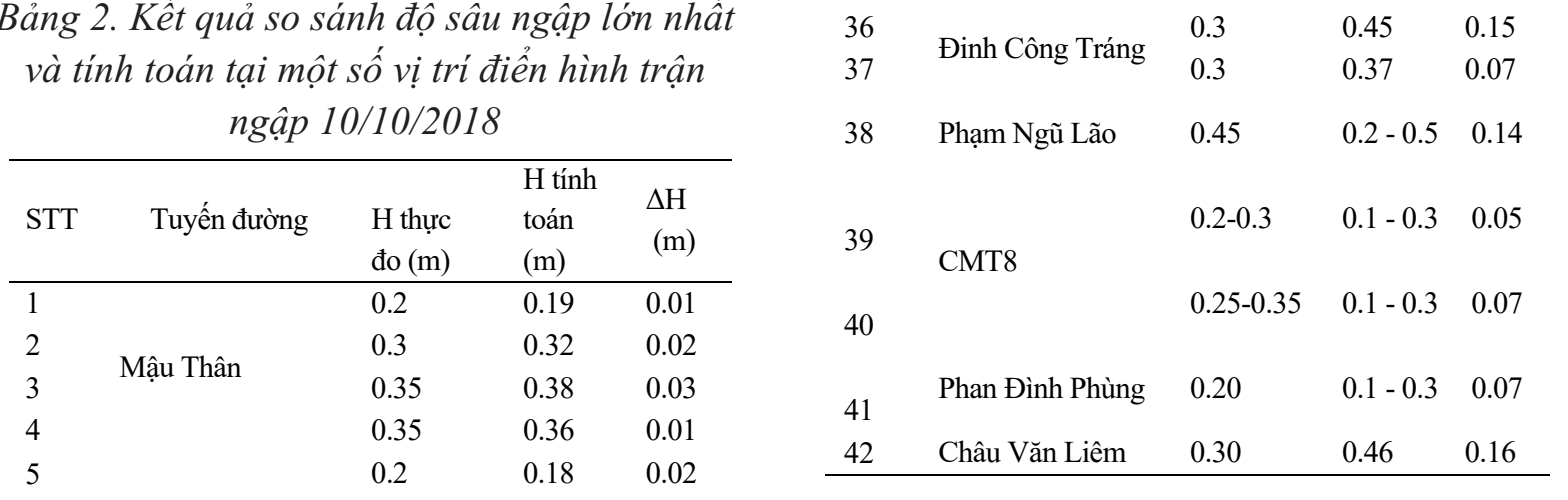

Đường 30 tháng $4 \quad 0.25 \quad 0.28 \quad 0.03$

$\begin{array}{lll}0.1 & 0.18 & 0.08\end{array}$

Trần Hưng Đạo $\quad 0.25 \quad 0.23 \quad 0.02$

$\begin{array}{lll}0.35 & 0.27 & 0.08\end{array}$

10

Nguyễn Văn Cừ

0.25

$0.17 \quad 0.08$

(

Châu Văn Liêm

0.35

$$
0.31
$$

0.04

12

13

14

15

16

17

18

19

20

21

22

23

24

25

26

27

28

29

30

31

32

33

34

35

$\begin{array}{llll}\text { Nguyễn An Ninh } & 0.30 & 0.35 & 0.05 \\ & 0.35 & 0.4 & 0.05 \\ & 0.65 & 0.56 & 0.09\end{array}$

Với trận ngập ngày 10/10/2018, xuất hiện nhiều tuyến đường ngập hơn, độ sâu ngập cũng lớn hơn. Các tuyến đường Mậu Thân, đường 30 tháng 4, đường Hòa Bình, Quang Trung, Châu Văn Liêm, Nguyễn An Ninh, Nguyễn Thái Học, Trần Hưng Đạo, Trần Bình Trọng...xuất hiện nhiều vùng ngập nặng, có vị trí ngập tới 0.7 $0.8 \mathrm{~m}$. Đồng thời xuất hiện thêm nhiều tuyến đường ngập mới.

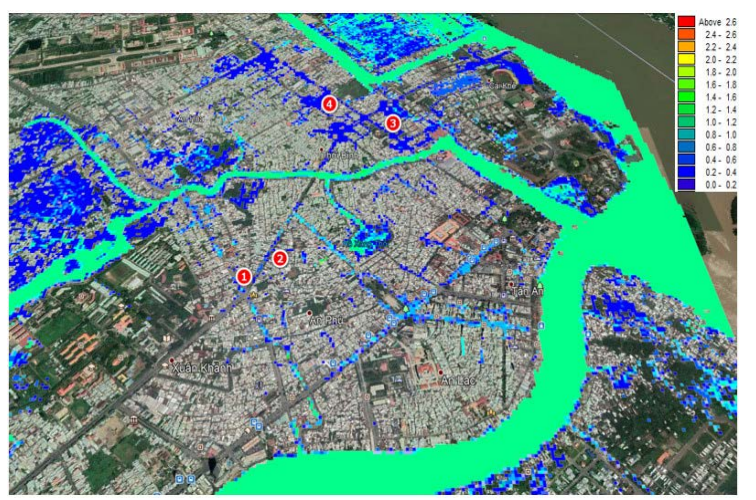

Hình 8. Kết quả mô phỏng trận mua ngày 3-5 tháng 10 năm 2018

Để tăng tính khẳng định của các thông số mô hình, trận mưa ngày 4 tháng 10 năm 2018 được đưa vào kiểm tra và kết quả cho thấy mô hình hoàn toàn đạt khả năng ứng dụng thực tế với độ chính xác mực nước dao động dưới $15 \mathrm{~cm}$.

Từ các kết quả tính toán trong 3 trận mưa, mô hình Mike Urban cho quận Ninh Kiều đã thể hiện các khu vực ngập úng đúng với thực tế so với đo đạc, hơn 40 điểm ngập đề đưa ra các kết quả chênh mực nước ngập sâu nhất với độ chính xác khá tốt, độ chênh lệch mực nước $\Delta \mathrm{H}=0.01$ - $0.15 \mathrm{~m}$, cụ thể chênh lớn nhất là $15 \mathrm{~cm}$ còn lại dao động trong khoảng 3-10 cm. 


\subsection{Xác định nguyên nhân ngập lụt}

Sau khi hiệu chỉnh kiểm định mô hình ngập lụt đô thị quân Ninh Kiều, các trường hợp mưa khác nhau có số liệu thực đo về mực nước ngập đã được tính toán để kiểm tra làm rõ hơn diễn biến ngập, phân tích các tác nhân đầu vào của mô hình (mưa, triều) và một số nguyên nhân đã được làm rõ:

- Quận Ninh Kiều là khu vực cao và có hệ thống đê phức tạp bao xung quanh, chỉ có các điểm xả ra sông Hậu là cánh cửa mở đối với các điều kiện biên ngoài. Trong lịch sự nước sông Hậu cũng không tràn bờ dâng lên khu vực Ninh Kiều cũng như lũ từ phía thượng nguồn rất ít ảnh hưởng đến.

- Nguyên nhân gây ngập chủ yếu là do triều, các cửa xả đều không có phai, van một chiều nên triều dâng ngược vào trong hệ thống và tràn ngược lên mặt đất rất nhanh. Rất nhiều đường ống được xây dựng cũ có độ sâu chôn ống lớn, thấp hơn nhiều so với mực nước max của sông Hậu cũng như triều cũng là các nhân tố tác động đến việc mỗi lần có triều cường là quận Ninh Kiều đều bị ngập nặng.

- Ngập do các trận mưa cực đoan xuất hiện ngày càng nhiều. Nhiều đoạn cống thoát cửa xả có đường kính cống nhỏ hơn đường kính cống của tuyến đường, do đó thoát nước không kịp, gây ngập cục bộ. Nhiều tuyến đường có chiều dài đường thoát nước khá xa nên khi mưa với lưu lượng lớn hệ thống chuyền tải không kịp, nước thoát chậm.

\section{Kết luận}

Mô hình Mike Urban đã khẳng định khả năng ứng dụng tính toán mô phỏng được hệ thống thoát nước trong điều kiện có ảnh hưởng của triều, cụ thể đã được hiệu chỉnh kiểm định với khu vực nghiên cứu quận Ninh Kiều thành phố Cần Thơ với 3 trận mưa khá điển hình trong năm 2018

Bằng việc sử dụng mô hình, quá trình diễn biến ngập lụt được mô phỏng lại chi tiết, sẽ giúp cho các nhà quản lý cũng như các chuyên gia kỹ thuật tìm hiểu phân tích được rõ ràng nguyên nhân gây ngập úng cho khu vực nghiên cứu.

Kết quả cho thấy định hướng sử dụng mô hình toán 2 chiều đã mang lại tính chính xác và chi tiết, tuy nhiên ngược lại nó cũng đòi hỏi yêu cầu về số liệu đầu vào cũng như sự chuẩn bị thiết lập mô hình chi tiết và phức tạp hơn so với các nghiên cứu về thủy văn đô thị khu vực Ninh Kiều trước đây.

\section{Tài liệu tham khảo}

1. Schmitt, T., Schilling, W., Sægrov, S., Nieschulz, K.P., (2002), Flood Risk Management for Urban Drainage Systems by Simulation and Optimization. Global Solutions for Urban Drainage, 114. Doi:10.1061/40644(2002)275.

2. TCVN 7957:2008 (2008), Thoát nước - mạng lưới và công trình bên ngoài - Tiêu chuẩn thiết kế.

3. Thorndahl, S., Willems, P., (2008), Probabilistic modelling of overflow, surcharge and flooding in urban drainage using the first-order reliability method and parameterization of local rain series. Water research, 42, 455-66. 10.1016/j.watres.2007.07.038.

4. Apirumanekul, C., Mark, O., (2001), Proceeding of 4th DHI Software Conference "Modelling of Urban Flooding in Dhaka City - Bangladesh".

5. Hung, N.Q., Babel, M.S., Weesakul, S., Tripathi, N.K., (2009), An Artificial neural network model for rainfall forecasting in Bangkok, Thailand. Hydrology and Earth System Sciences, 13 (8), 1413-1425. Doi:10.5194/hess-13-1413-2009. 


\title{
APPLICATION OF 2D HYDROLOGICAL MODEL FOR URBAN COASTAL AREA - A CASE STUDY IN NINH KIEU, CAN THO Nguyen Quang Hung ${ }^{*}$, Nguyen Phuoc Tho ${ }^{2}$
}

${ }^{1}$ Faculty of Meteorology, Hydrology, and Oceanography, VNU University of Science, Vietnam National University, Hanoi

${ }^{2}$ Regional center for Meteo-Hydrology of Can Tho

\begin{abstract}
Urban flooding is becoming an increasingly urgent and noisy problem in daily life of people. The urban hydrology model applicable proof by many researchs that it able to simulate the rainfall runoff, hydraulic in pipe and canal, inundation situation in the urban area. In this study, the authors used Mike Urban software to assess the ability simulating tidal influences in the drainage system of Ninh Kieu district, Can Tho city. The results show that the flooding progress due to rainfall, flood surges, as well as drainage problems have been fully described. From the model's results, the causes of inundation was identified, and solutions have been proposed to cope with complicated developments in the future such as climate change, sea level rise. The result also confirms the practical application power of two-dimensional hydraulic hydrological models in the design, operation and management of urban drainage for coastal cities.
\end{abstract}

Keywords: Urban hydrological modeling, inundation, rising tidal, sustainable urban development. 